International Journal of Research in Advent Technology, Vol.7, No.4, April 2019

E-ISSN: 2321-9637

Available online at $w w w . i j r a t . o r g$

\title{
Fabrication and Experimental Analysis Of Micro Electro Discharge Machining
}

\author{
Ananthan D Thampi ${ }^{1}$, Prof. Sureshkumar V B ${ }^{2}$, Lislin Luka ${ }^{3}$ \\ ${ }^{1,3}$ M.Tech Manufacturing and Automation, ${ }^{2}$ Assistant Professor, Department of Mechanical \\ Engineering, College of Engineering, Trivandrum, Kerala 695016, India
}

\begin{abstract}
Electro Discharge Machining (EDM) is an electro-thermal non-traditional machining process. The importance of this machining process is increasing due to the requirement of high precision, complex shapes and high surface finish. In EDM various techniques are applied to improve the material removal rate (MRR), surface roughness (SR) and tool wear rate (TWR) with different electrical parameter combination. From the literature review, it was noted that most works focused only on EDM's electrical parameters. The present work focused not only on electrical parameters but also on the non-electrical parameters of EDM. A MicroEDM spark generating circuit was created for this work and then experiments were performed to analyze the effect of machining parameters like Input voltage $(\mathrm{V})$, work piece material (Al, A356 alloy), dielectric medium (kerosene, deionized water) over the responses of MRR and TWR in terms of mg per spark.
\end{abstract}

Keywords - EDM, Micro manufacturing, Non-traditional machining, Spark erosion, Dielectric medium.

\section{INTRODUCTION}

The demand for miniature components in different industries are growing day by day. Micro EDM is a very promising machining operation to meet the requirements in the production field due to the high precision, surface finish and simplicity. This metal cutting process is mainly used for hard metals or those materials which are difficult to cut with traditional techniques. The working principle of EDM is that it converts electrical energy into thermal energy of spark. In this machining process the material from the work piece is removed by the controlled wearing action caused due to the repeatedly occurring spark ejection between the tool and work piece immersed in a dielectric fluid. Here the machining takes place mainly due to spot vaporization of the metallic particle and melting. The new developments in the field of materials like alloys, composites, etc. has increased the importance of EDM. EDM can easily machine any electrically conductive materials regardless of its hardness and complexity. So it is necessary to make further developments in this machining process. Nowadays innovation in EDM focus mainly on the production of micro and nanoscale features, with $\mathrm{CNC}$ control system and advanced spark generator to improve the efficiency of machining [8,9].

\section{DETAILS OF MICRO EDM SETUP}

\subsection{Spark generating circuit}

In this work, an in-house EDM spark generating circuit was developed. The circuit used is an R-C type which consists of:

- Cap1, Cap2 - capacitors $(220 \mu \mathrm{F}, 450 \mathrm{~V})$ and $(3300 \mu \mathrm{F}, 350 \mathrm{~V})$.

- ES1, ES2 - Electronic switches (IGBT)

FGA25N120 ANTD

- $\mathrm{R}$ - Resistor (100 Ohm, 10W)

- $\mathrm{L}-$ Inductor $(1 \mathrm{mH})$.
The spark (Pulsed DC) can be formed from an electric circuit which mainly undergo three different steps of operation:

Step 1: Conversion of AC to DC.

Step 2: Charging of Cap2.

Step 3: Discharging of Cap2 between the tool and work piece gap.

In step 1 operation, the $\mathrm{AC}$ power supply is converted in to DC by using a Wheat stones full bridge rectifier. This DC power is then stored in capacitor Cap1 as shown in fig. 1. This capacitor Cap 1 will be the source of energy for the discharging capacitor Cap2 in step 2 operation. The main reason to use capacitor Cap1 is that it will supply a uniform energy at the input of capacitor Cap2, so that any variations occurring in the AC supply voltage will not affect the discharge voltage. The charging circuit of Cap2 is Cap1-ES1L-Cap2-R-Cap1 and the charging time for Cap2 is approximately 350 milliseconds. The charging and discharging of Cap2 is controlled by using IGBT (Insulated Gate Bipolar Transistor) ES1 and ES2. On charging, ES1 must be ON and ES2 must be OFF. On discharging, ES1 must be OFF and ES2 must be ON. The inductor L is placed in the circuit as a protection to avoiding the sudden rise in supply current. Fly wheel diode (FWD) are used across inductive coils to prevent voltage fluctuations when the power is turned off. In step 3 operation, discharging of capacitor Cap2 will take place between the tool and work piece. The resistor $\mathrm{R}$ is provided in the circuit to prevent the excess flow of current through circuit. Once the discharging operation is finished then immediately charging operation will be started. The pulse on time and pulse off time are maintained at $50 \mu$ s. The two IGBT switches ES1 and ES2 are controlled by a trigger circuit. This trigger circuit consist of a micro-controller and an opto-coupler. The micro-controller used in this work is an ARDUINO UNO R3 board and it is power using a 9V adapter. 


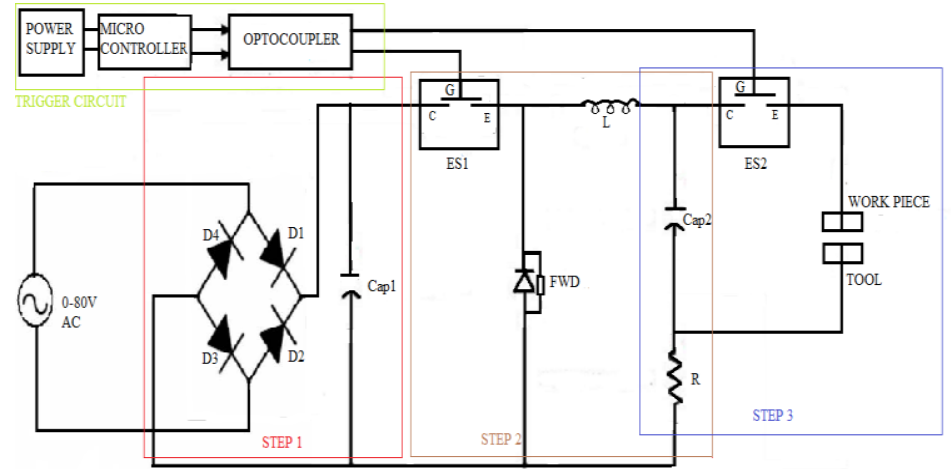

Fig 1. Layout of the electrical circuit. [10]

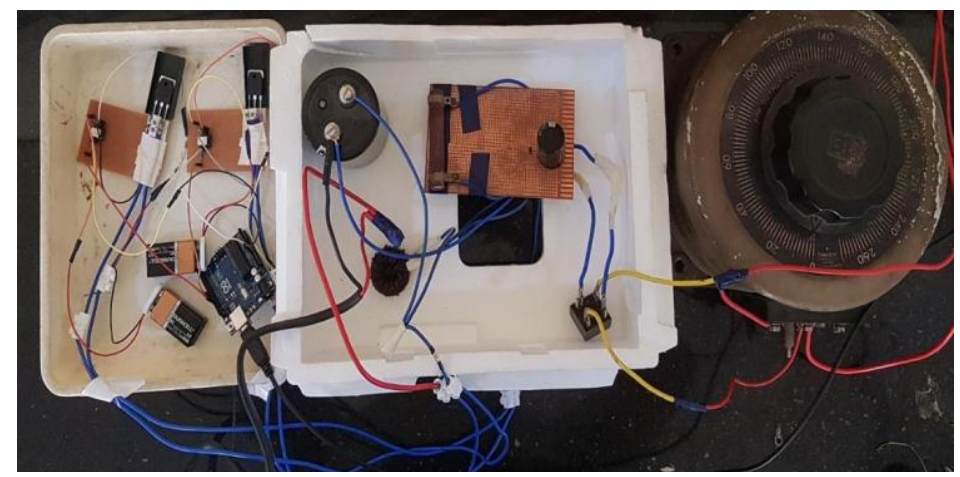

Fig 2. Electrical circuit controlled by a micro-controller

const int $s 1=13$;

const int $s 2=11 ;$

// the setup function runs once when you press reset or power the board void setup () 1

pinMode (s1, OUTPUT):

pinMode (s2, OUTPUT):$$
\text { ) }
$$

// the loop function runs over and over again forever

void loop () (

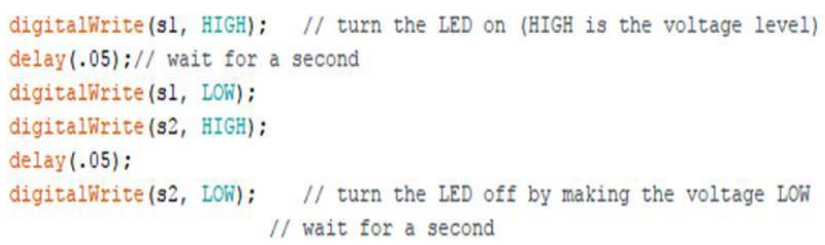

Fig 3. Logic for Arduino Microcontroller

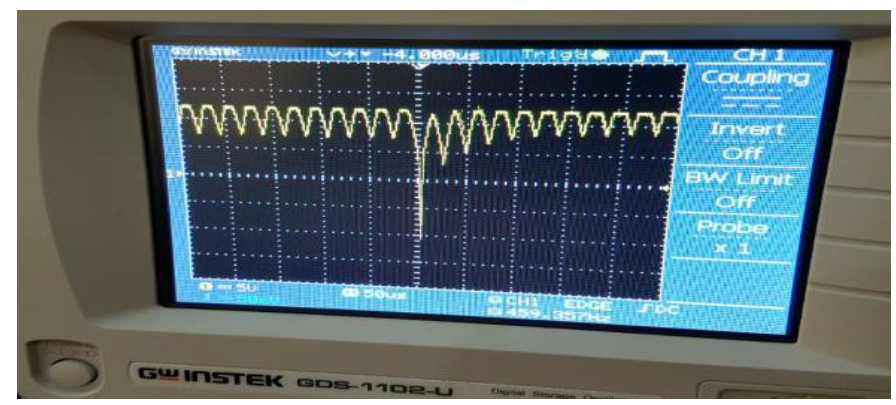

Fig 4. Output from Arduino
Usually in an industry for switching sequences, PLC (Programmable logic controller) is commonly used but the cost of PLC is very high, so to reduce the cost of fabrication in this work, a micro-controller was used. Micro-controller is cheaper compared to PLC but chances for hardware failure is high so as to protect the micro-controller an opto-coupler circuit is connected between the microcontroller and IGBT.
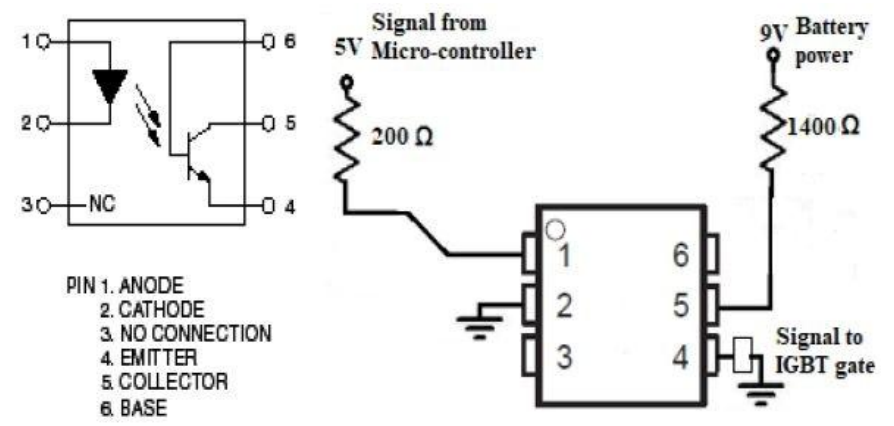

Fig 5. Opto-coupler and circuit to transfer signal to IGBT.

Opto-coupler is a component that is used to transfer the electrical signals between two isolated circuits by using light. They prevent high voltages from affecting the system receiving the signal. The Opto-coupler used in this work is MCT2E215Q.

\subsection{Dielectric circulation unit}

The dielectric fluid is circulated by a 220V, $15 \mathrm{~W}$ Motor which is having a discharge rate of $800 \mathrm{~L} / \mathrm{hr}$. The dielectric medium used in this work was deionized water and kerosene. The dielectric is filtered in order to remove the debris from the dielectric medium.

\subsection{Details of tool and work piece}

$\mathrm{Al}$ and A356 alloy work pieces have been spark eroded using copper as tool material. The work piece $\mathrm{Al}$ is softer than $\mathrm{A} 356$ alloy. The tool electrode is the most critical part in the EDM. Copper has been chosen as the electrode material because of its lower electrical and thermal resistance. The tool diameter has been taken as $1 \mathrm{~mm}$. The length of the electrode has been kept at $100 \mathrm{~mm}$ so that maximum transfer of heat is possible away from the tool tip.

\section{EXPERIMENTAL PROCEDURE}

Initially the work piece and tool were properly cleaned, dried and then the weight of both the work piece and tool were noted. After that the work piece was placed in a container filled with dielectric medium, so that the tool and work piece will be in a submerged condition. Then switch $\mathbf{O N}$ the power supply for the spark generating electrical circuit, arduino board (Micro-controller) and dielectric circulating unit. Now manually move the tool towards the work piece and spark erosion will take place on the surface of work piece. Total fifty sparks were induced on the surface of the work piece. After that the work piece and tool were again cleaned, dried 


\section{Available online at www.ijrat.org}

and their weight was noted. So the difference in weight will give the Tool Wear Rate (TWR) and Material Removal Rate (MRR). In order to avoid human error caused due to manual movement of tool towards the surface of work piece,this above mentioned same procedure was repeated again thrice for the same machining condition and the average of TWR and MRR was considered finally as the result of the experiment conducted. The process parameters and levels of these parameters for this work were finalized after conducting a literature survey in the field of EDM.

\begin{tabular}{|c|c|c|c|c|}
\hline PROCESS & \multicolumn{4}{|c|}{ LEVEL } \\
\hline NPUT VOLTAGE(V) & 40 & 50 & 60 & 70 \\
\hline $\begin{array}{l}\text { WORK PIECE } \\
\text { MATERIAL }\end{array}$ & \multicolumn{2}{|c|}{ ALUMINIUM } & \multicolumn{2}{|c|}{ A 356 ALLOY } \\
\hline $\begin{array}{c}\text { DIELECTRIC } \\
\text { MEDIUM }\end{array}$ & \multicolumn{2}{|c|}{ KEROSENE } & \multicolumn{2}{|c|}{ DEIONISED WATER } \\
\hline TOOL MATERIAL & \multicolumn{4}{|c|}{ COPPER (IMM DIAMETER) } \\
\hline PULSE ON TIME & \multicolumn{4}{|c|}{$50 \mu S$} \\
\hline PUISE OFF TIME & \multicolumn{4}{|c|}{$50 \mu \mathrm{S}$} \\
\hline
\end{tabular}

Table 1. Process parameters considered and its level

\section{RESULTS AND DISCUSSION}

In this study, the machining parameters mainly considered were input voltage, work piece material, dielectric medium whereas parameters like tool material, pulse on time and pulse off time were maintained constant. The performance measure analyzed were MRR, TWR and the ratio of MRR to TWR. The equations used to calculate MRR and TWR are given below:

$$
\operatorname{MRR}=\frac{W 1 b-W 1 a}{N} \quad \quad \operatorname{TWR}=\frac{W 2 b-W 2 a}{N}
$$

Where,

W1b-Weight of work piece before spark erosion

W1a- Weight of work piece after spark erosion

W2b-Weight of tool before spark erosion

W2a- Weight of tool after spark erosion

$\mathrm{N}$ - Number of spark induced on the surface of work piece $=$ 50 .

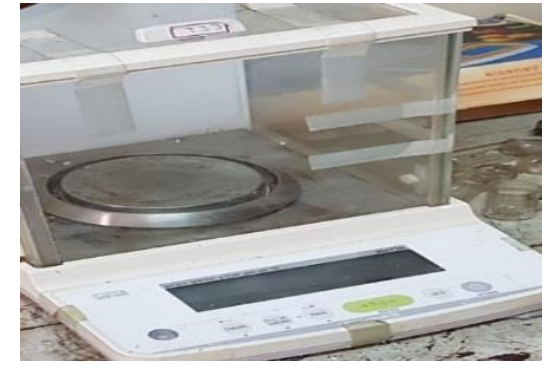

Fig 6. Weight of tool and work piece was measured using SHIMADZU ATY224

\subsection{Material removal rate (MRR)}

It was found that the Input voltage, work piece material and change in dielectric medium are the significant factors which influences the MRR. When the input voltage was increased, the MRR also increased. When the work piece material was changed to A356, it was noted that the MRR was low compared to the MRR when the work piece was Al. This is mainly because of the difference in hardness and properties of the work piece material. Similarly, when the dielectric fluid was changed to kerosene, it was noted that the MRR was high compared to the MRR when the dielectric was deionized water.
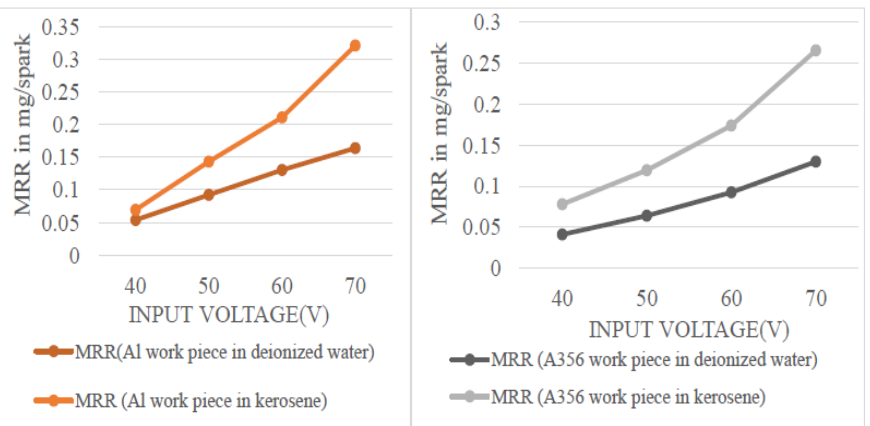

Graph 1. Effect of input voltage, dielectric medium and work piece material on MRR.

\subsection{Tool wear rate (TWR)}

When the input voltage was increased, the TWR also increased. When the Al work piece was immersed in deionized water, it was noted that the TWR was higher than the TWR of Al immersed in kerosene. Similarly, when the A356 work piece was immersed in deionized water, it was noted that the TWR was lower than the TWR of A356 immersed in kerosene but at 40V, TWR for A356 immersed in kerosene was lower than A356 in deionized water. So the effect of each parameter depends on the other parameters present at the same time. 


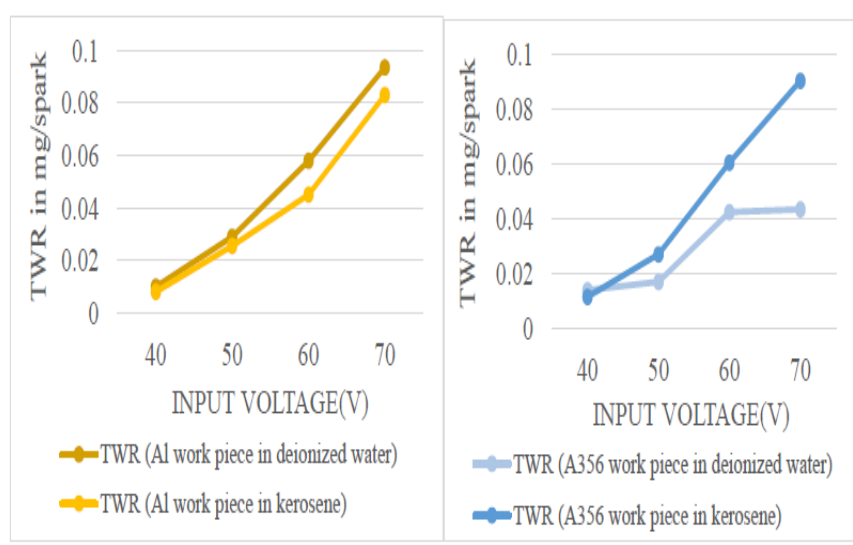

Graph 2. Effect of input voltage, dielectric medium and work piece material on TWR.

\subsection{Ratio of MRR to TWR}

While machining the most important requirement is to have a high MRR and low TWR. So the ratio of MRR to TWR is a significant factor that need to be considered. For a better machining, we need to have a high value for the ratio of MRR to TWR. The ratio depends on the change in input voltage, dielectric medium used and work piece material.



Graph 3. Effect of input voltage, dielectric medium and work piece material on MRR/TWR.

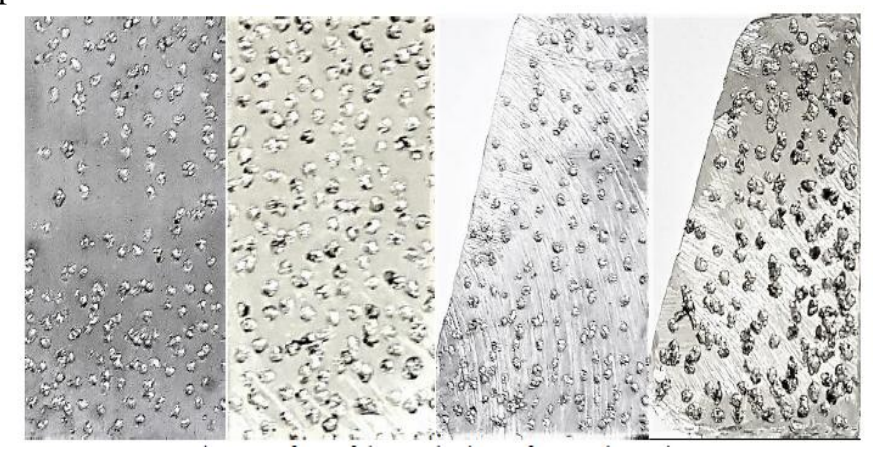

Fig 7. Surface of the work piece after spark erosion

\section{CONCLUSION}

In this work, a Micro-EDM was fabricated and experimental analysis was conducted to know the effect of machining outputs taken for consideration are material removal rate and tool wear rate of the $\mathrm{Al}$ and $\mathrm{A} 356$ work piece using the copper tool with jet flushing method. Both these outputs are important in industrial applications. The experiment depended mainly on various process parameters such as input voltage (V), dielectric medium and work piece material. The Pulse on and pulse off time were maintained constant at $50 \mu$ s. Based on the different combination and levels of parameters total 16 experiments were conducted. The following points are concluded from the results obtained in the experiment:

- Using kerosene as a dielectric medium will be better than deionized water. The maximum MRR using kerosene for Al was noted as $0.321 \mathrm{mg} / \mathrm{spark}$, while using deionized water it was noted as $0.164 \mathrm{mg} / \mathrm{spark}$. The maximum MRR using kerosene for A356 was noted as $0.266 \mathrm{mg} / \mathrm{spark}$, while using deionized water it was noted as $0.13 \mathrm{mg} / \mathrm{spark}$. The MRR using kerosene is found to be $50 \%$ more than MRR using deionized water.

- When the Input Voltage increases, MRR and TWR both increases but the ratio of MRR to TWR was decreasing. The maximum MRR/TWR using kerosene for $\mathrm{Al}$ was noted as 8.69 , while using deionized water it was noted as 5.4 The maximum MRR/TWR using kerosene for A356 was noted as 6.78 , while using deionized water it was noted as 3.77. Most of these maximum values occurred at $40 \mathrm{~V}$. So in order to reduce TWR it is better to machine in low Input voltage.

- From the literature survey it was evidential that only electrical parameters were considered for process parameter optimization but from this work, it can be concluded that not only electrical parameters but also non electrical parameters plays an important role in EDM machining like change in dielectric medium, change in work piece properties, etc. have its own importance. So while optimizing the process parameter of EDM, nonelectrical parameters should also be considered.

\section{REFERENCES}

[1] M. Mustafaiz Ahmad, A Parametric Experimental Design Study of EDM Process Parameters in Machining of Titanium Grade 2, International Journal of Aerospace and Mechanical Engineering Volume 3, August 2016.

[2] Arul Dass james.D, Experimental Study of Eco-friendly Wire-Cut Electrical Discharge Machining, International Journal of Innovative Research in Science, Engineering and Technology Vol. 5, Issue 1, 2016.

[3] Trupti G. Raut, A Review on Optimization of Machining Parameters in EDM, International Journal of Innovative Research in Science, Engineering and Technology, Vol. 4, Issue 3, March 2015.

[4] M.P.Jahan Pegah Kakavand, E.L.M. Kwang, M.Rahman, Y.S.Wong, 2014, An Experimental invesigation into the micro electric discharge machining behaviour of Aluminium alloy (AA 2024), Int. Journal of Advanced Manufacturing Technology.

[5] P.S. Rao, Performance of a Low Cost Tabletop Die Sinker Electric Discharge Machining [EDM] unit, International 
Journal of Modern Engineering Research, Vol.2, Issue.3, May June 2012 pp-1320-1325.

[6] Ashok Kumar, Experimental Investigation of Machine Parameters for EDM Using U shaped electrode of EN-19 tool steel, International Journal of Engineering Research and Applications (IJERA) ISSN: 2248-9622, Vol. 1, Issue 4, 2011, pp.1674-1684 1674.

[7] Fuqiang Hu B.Y.Song, J.C.Bail, P.J.Hou, H.C.Chen and H.Zhang, 2010, Micro EDM for an Aluminium Matrix Composite, Key Engineering Materials, Vols. 447-448.

[8] Jose Mathew, V.B.Suresh Kumar, Somashekhar K.P, Investigation into the influence of process parameters on Micro Wire EDM, Fifth International Conference on Precision,Meso,Micro and Nano Engineering,College of Engineering, Trivandrum, India, Dec 2007,pp.287-293.

[9] Jose Mathew, Hashim V, Sooraj V.S, M.Rahman, Experimental analysis of micro hole making in die steel using Micro Electric Discharge Machining, Fifth International Conference on Precision,Meso,Micro and Nano Engineering, College of Engineering, Trivandrum, India, Dec 2007,pp.279285.

[10] https://data.epo.org/publicationserver/rest/v1.0/publicationdates/20101006/patents/EP1749609NWB1/docu-ment.html. 